\title{
Usefulness of plasma full-length glypican-3 as a predictive marker of hepatocellular carcinoma recurrence after radial surgery
}

\author{
MASAHIRO MIURA $^{1}$, NORIHIRO FUJINAMI ${ }^{2}$, YASUHIRO SHIMIZU ${ }^{2}$, SHOICHI MIZUNO $^{2}$, \\ KEIGO SAITO $^{2}$, TOSHIHIRO SUZUKI ${ }^{2}$, MASARU KONISHI ${ }^{3}$, SHINICHIRO TAKAHASHI ${ }^{3}$, \\ NAOTO GOTOHDA $^{3}$, KOUZOU SUTO ${ }^{1}$, TOMOKAZU YOSHIDA ${ }^{1}$ and TETSUYA NAKATSURA ${ }^{2}$ \\ ${ }^{1}$ Central Research Laboratories, Sysmex Corporation, Kobe, Hyōgo 651-2271; ${ }^{2}$ Division of Cancer Immunotherapy, \\ Exploratory Oncology Research and Clinical Trial Center, National Cancer Center; ${ }^{3}$ Division of Hepatobiliary \\ Pancreatic Surgery, National Cancer Center Hospital East, Kashiwa, Chiba 277-8577, Japan
}

Received June 14, 2019; Accepted October 31, 2019

DOI: $10.3892 / \mathrm{ol} .2020 .11371$

\begin{abstract}
Predicting the risk of hepatocellular carcinoma $(\mathrm{HCC})$ recurrence before treatment is necessary for developing subsequent treatment policies. Several tumor markers found in blood, such as alpha-fetoprotein (AFP) and protein induced by vitamin $\mathrm{K}$ absence or antagonist-II (PIVKA-II), are presently used to determine the occurrence and recurrence of $\mathrm{HCC}$ and to predict patient prognosis. However, these markers are insufficient for these purposes as certain patients have HCC recurrence despite exhibiting negative AFP and PIVKA-II. The present study identified glypican-3 (GPC3), an embryonal carcinoma antigen that is expressed specifically in HCC and is secreted into blood. Although the N-terminal domain of GPC3 in sera may be a potential prognostic factor for $\mathrm{HCC}$, its biological role remains unclear. By contrast, full-length GPC3 (FL-GPC3) is reported to serve important roles in cell differentiation, proliferation and signaling events that cause HCC. Given the biological roles of FL-GPC3 in HCC progression, the present study evaluated its potential as a predictive marker of HCC recurrence. In the present study, a novel measurement system was constructed to specifically measure plasma FL-GPC3. Subsequently, its ability to predict recurrence after radical surgery in 39 HCC patients was evaluated. The results revealed that preoperative
\end{abstract}

Correspondence to: Professor Tetsuya Nakatsura, Division of Cancer Immunotherapy, Exploratory Oncology Research and Clinical Trial Center, National Cancer Center, 6-5-1 Kashiwanoha, Kashiwa, Chiba 277-8577, Japan

E-mail: tnakatsu@east.ncc.go.jp

Abbreviations: HCC, hepatocellular carcinoma; AFP, alphafetoprotein; PIVKA-II, protein induced by vitamin $\mathrm{K}$ absence or antagonist-II; GPC3, glypican-3; FL-GPC3, full-length glypican-3; ROC, receiver operating characteristic; AUC, area under the curve

Key words: glypican-3, hepatocellular carcinoma, tumor marker, alpha-fetoprotein, protein induced by vitamin $\mathrm{K}$ absence or antagonist-II
FL-GPC3 levels in patients with recurrence were significantly higher than those in patients without recurrence, suggesting that FL-GPC3 could be a better predictive maker of risk of recurrence than AFP or PIVKA-II. Furthermore, it was determined that the combination of FL-GPC3, AFP and PIVKA-II could predict recurrence within one year of radical surgery with high sensitivity and specificity. Based on these results, the validation of FL-GPC3 as a predictive marker of HCC recurrence in a larger population is warranted.

\section{Introduction}

Hepatocellular carcinoma (HCC) is one of the most common forms of cancer. The prognosis of patients with HCC is generally poor, and it is the third leading cause of cancer mortality worldwide (1). The recurrence rate within five years of surgical resection or radiofrequency ablation for HCC is estimated at $70 \%$, which contributes to the poor prognosis (2). To improve prognosis, it is important to diagnose recurrence at an early phase and begin appropriate additional therapies. Although numerous methods for predicting recurrence have been studied, effective prediction methods have not yet been established $(3,4)$. At present, alpha-fetoprotein (AFP) and protein induced by vitamin $\mathrm{K}$ absence or antagonist-II (PIVKA-II) are commonly used as tumor markers and are reported to be prognostic factors of HCC (3). However, these markers are sometimes elevated in patients without HCC who suffer from chronic hepatitis (5). Thus, novel diagnostic markers to detect $\mathrm{HCC}$ with greater sensitivity and specificity are urgently needed.

In this study, we noted glypican-3 (GPC3), a protein of about $70 \mathrm{kDa}$, that attaches to the cell membrane via glycosylphosphatidylinositol anchors and is expressed in approximately $70 \%$ of HCC cases (6-8). GPC3 has multiple sugar chains and heparan sulfate modification sites and is known to be related to poor prognosis for HCC (9-12). GPC3 undergoes cleavage at its central region (R358/S359) by an enzyme called Furin into a N-terminal form of about $40 \mathrm{kDa}$ and a C-terminal form of about $30 \mathrm{kDa}$ (13). GPC3 is also thought to exist in a full-length form, the same as the membrane-bound state, with numerous intermolecular disulfide bonds $(14,15)$. 
GPC3 is present in the blood of HCC patients $(16,17)$. However, the molecular form of GPC3 in blood is still being debated and there are various opinions about the soluble form, such as full-length and $\mathrm{N}$-terminal forms $(18,19)$. Furthermore, levels of GPC3 in blood differ across reports, with values ranging from several $\mathrm{pg} / \mathrm{ml}$ to several $\mu \mathrm{g} / \mathrm{ml}(12,15,19-22)$. Although the roles of GPC3 and its physiological significance have not yet been elucidated, it is thought to relate to the regulation of cell differentiation and proliferation and to exert these functions only after being cleaved and configured into the full-length form by the disulfide bond between $\mathrm{N}$ - and C-terminal domains $(13,23)$.

There have been several reports about the clinical usefulness of the N-terminal form of GPC3. Enzyme-linked immunosorbent assay methods capable of detecting the $\mathrm{N}$-terminal form of GPC3 have indicated that preoperative N-terminal GPC3 is an independent biomarker of HCC recurrence $(15,19,20)$. However, it remains controversial whether full-length GPC3 (FL-GPC3) is a predictive marker of HCC recurrence. Thus, we developed a new measurement reagent to specifically detect FL-GPC3 and verified its utility for predicting HCC recurrence after radial surgery, using FL-GPC3 alone or in combination with the conventional tumor markers AFP and PIVKA-II.

\section{Materials and methods}

Samples. Preoperative serum and plasma samples were collected from 39 patients with HCC who underwent surgical resection at the National Cancer Research Center East Hospital, Japan. All samples were frozen and stored at $-80^{\circ} \mathrm{C}$ until measurement. Written informed consent was obtained from all patients.

Measurement of plasma FL-GPC3, AFP, or PIVKA-II. AFP and PIVKA-II were measured using an electrochemiluminescence immunoassay kit (Roche Co.) and chemiluminescent enzyme immunoassay kit (Eisai Co.), respectively. The assay system for FL-GPC3 was constructed using a sandwich immunoassay, in which a monoclonal mouse antibody against its $\mathrm{N}$-terminus is used to capture the protein and a monoclonal mouse antibody against the $\mathrm{C}$-terminus is used to detect the protein. The monoclonal antibody against its $\mathrm{N}$-terminus was labeled with biotin and the antibody against its C-terminus with alkaline phosphatase. The immunoassay was performed by first reacting the plasma sample with the biotinylated antibody, then capturing the immunocomplex using streptavidin-coated magnetic beads. After washing the beads, an alkaline phosphatase-labeled antibody was added to form a sandwich immunocomplex. After a second wash, a luminescent substrate was added and the luminescence intensity was measured. All immunoassay steps were performed using a HISCL ${ }^{\mathrm{TM}}$ series (Sysmex Co.), which is an automated immunoassay device. Recombinant GPC3 (R\&D Systems Inc.) was used as the assay standard. Standards at concentrations of $2,15,50,150,500$, and $1,500 \mathrm{pg} / \mathrm{ml}$ were measured and calibration curves were generated by the four-parameter logistic regression method.

Detecting FL-GPC3 in blood. HepG2 (ATCC HB-8065), a GPC3-positive liver cancer cell line, was purchased from American Type Culture Collection. This cell line was authenticated using STR DNA profiling by PowerPlex ${ }^{\circledR} 16$ HS system (Promega KK. The Cells were seeded at $1.6 \times 10^{5}$ cells $/ \mathrm{ml}$ and cultured in $250 \mathrm{ml}$ of Dulbecco's modified Eagle's medium D5796 (Sigma-Aldrich) with 10\% fetal bovine serum (Thermo Fisher Scientific, Inc.) for 3 days. The culture supernatant was recovered, filtered through a $0.22 \mu \mathrm{m}$ filter, and concentrated 20 -fold by centrifugal filters ( $3 \mathrm{kDa} \mathrm{MWCO}$ ). $\mathrm{NaCl}$ was added to a final concentration of $400 \mathrm{mM}$ and Tween-20 was added to a final concentration of $0.1 \%$, after which $50 \mu \mathrm{g}$ biotinylated $\mathrm{N}$-terminal recognizing antibody and streptavidin-immobilized beads were added. After reacting at $4^{\circ} \mathrm{C}$ for $12 \mathrm{~h}$, beads were collected and washed eight times with $1 \mathrm{ml}$ of $0.1 \%$ Tween/PBS. The bound immunocomplex was then eluted with $0.5 \mathrm{ml}$ of $0.1 \mathrm{M}$ Glycine-HCl pH 2.5/0.1\% Tween-20. After concentrating the eluate with centrifugal filters, $1 / 5$ of the volume was used for Western blotting and 4/5 was used for analysis by mass spectrometry. For Western blotting analysis, the sample after immunoprecipitation and recombinant FL-GPC3 were fractionated by SDS-PAGE and transferred to a PVDF membrane. Membranes were washed with $0.1 \%$ Tween/TBS three times after incubation with $3 \% \mathrm{BSA} / 1 \%$ Tween/TBS for $60 \mathrm{~min}$ and incubated with $0.1 \mu \mathrm{g} / \mathrm{ml}$ of primary antibodies to detect the C-terminus region of GPC3 for $60 \mathrm{~min}$. Next, membranes were washed three times and incubated with secondary anti-mouse antibodies conjugated with HRP (dilution, 1:5,000; Cat. No. 330; Medical and Biological Laboratories Co., Ltd.) for $60 \mathrm{~min}$. After washing three times, membranes were incubated with a chemical substrate and measured using the ECL system LAS-3000 mini (Fuji Firm Co.) according to the manufacturer's protocols. For mass spectrometry, reverse phase chromatography was carried out with a L-column Micro $(0.1 \times 150 \mathrm{~mm}$, Chemical Substance Evaluation Research Organization) connected to an ADVANCE UHPLC SYSTEM (Michrom BioResources, Inc.) using a Thermo Scientific LTQ Orbitrap XL mass spectrometer. Measurement was performed under conditions of $0.1 \%$ formic acid with acetonitrile as a solvent at a flow rate of $500 \mathrm{nl} / \mathrm{min}$. The ionization method was performed under conditions of Nanoflow-LC-ESI with a positive ionization mode, capillary voltage $1.9 \mathrm{kV}$, and collision energy $35 \%$.

Statistical analysis. Statistical analyses were performed using Statflex software (Nankodo, Tokyo, Japan). Patient characteristics were compared by the Fisher's exact tests for nominal variable and the Mann-Whitney U test for continuous variables. Survival rates were analyzed by the Kaplan-Meier method and log rank test. The cutoff values were determined by receiver operating characteristic (ROC) curves and area under the curve (AUC) analyses, and Spearman rank correlation was used for correlation analysis. Statistical significance was defined as $\mathrm{P}<0.05$.

\section{Results}

Patient characteristics. Table I shows the characteristics of 39 patients with HCC. The median patient age was 67 years (range: 59-71 years) and 31 (79\%) were male. 31 patients (79\%) had a hepatic virus infection, 23 of them with HCV and eight with HBV. Of the total 39 patients, 11 had no recurrence of HCC within 4 years (non-recurrence group) and 28 had recurrence (recurrence group). Among the recurrence group, 15 
Table I. Patient characteristics.

\begin{tabular}{|c|c|}
\hline Variables & Number \\
\hline Age, median (range) & $67(59-71)$ \\
\hline \multicolumn{2}{|l|}{ Sex } \\
\hline Male & 31 \\
\hline Female & 8 \\
\hline \multicolumn{2}{|l|}{ Liver condition } \\
\hline Cirrhosis & 13 \\
\hline Chronic hepatitis & 15 \\
\hline Other & 11 \\
\hline \multicolumn{2}{|l|}{ Virus infection } \\
\hline $\mathrm{HCV}$ & 23 \\
\hline $\mathrm{HBV}$ & 8 \\
\hline None & 8 \\
\hline \multicolumn{2}{|l|}{ TNM stage } \\
\hline I & 22 \\
\hline II & 8 \\
\hline III & 6 \\
\hline IV & 2 \\
\hline \multicolumn{2}{|l|}{ Number of tumors } \\
\hline Solitary & 8 \\
\hline Multiple & 31 \\
\hline Tumor size (mm), median (range) & $40.0(25.0-67.5)$ \\
\hline \multicolumn{2}{|l|}{ Vascular invasion } \\
\hline Present & 11 \\
\hline Absent & 28 \\
\hline \multicolumn{2}{|l|}{ Differentiation of tumor } \\
\hline Well & 8 \\
\hline Moderately & 28 \\
\hline Poorly & 3 \\
\hline \multicolumn{2}{|l|}{ Recurrence } \\
\hline Yes & 28 \\
\hline No & 11 \\
\hline AFP (ng/ml), median (range) & $28.5(5.7-294.6)$ \\
\hline PIVKA-II (mAU/ml), median (range) & $97.0(26.5-508.5)$ \\
\hline FL-GPC3 (pg/ml), median (range) & $21.0(4.0-55.6)$ \\
\hline
\end{tabular}

$\mathrm{HCV}$, hepatitis C virus; HBV, hepatitis B virus; $\mathrm{AFP}$, alpha-fetoprotein; PIVKA-II, protein induced by vitamin $\mathrm{K}$ absence or antagonist-II; FL-GPC3, full-length glypican-3.

of 28 patients had early recurrence within 1 year (Table II). Furthermore, six of the 15 patients with early recurrence were stage III or higher, while the other nine patients were stage II or lower, who were thought to have a relatively low risk of recurrence (24).

Proof of existence of FL-GPC3 in cultured cell supernatant. To verify the presence of FL-GPC3 in blood, we evaluated secreted GPC 3 in the supernatant of cultured HepG2 cells, which has been well characterized as a GPC3-positive liver cancer cell line (25). We used mass spectrometry to detect
FL-GPC3 containing both the N- and C-terminal domains. HepG2 cultured supernatant was used based on the following two conjectures: (i) Proteins secreted from HepG2 cells into supernatant are potentially the same as those secreted from liver cancer cells into blood in vivo and (ii) using immunoprecipitation with mass spectrometry to directly detect FL-GPC3 in blood would require much higher sensitivity ( $\mathrm{pg} / \mathrm{ml}$ order) than the currently measurable value. GPC3 in the supernatant of cultured cells was recovered by immunoprecipitation with the N-terminal recognition antibody and confirmed by Western blotting with the C-terminal recognizing antibody (Fig. 1A). The molecular weight of the captured GPC3 was the same as that of the full-length recombinant GPC3, which was run alongside for comparison. To confirm the existence of both the $\mathrm{N}$ - and C-terminal domains, analysis by mass spectrometry was performed. Many peptides derived from both the N- and C-terminals of GPC3 were detected (Table SI). It was thus confirmed that FL-GPC3 was present in the culture supernatant, implying a high likelihood of FL-GPC3 being present in blood.

Construction of a measurement method for FL-GPC3. To measure FL-GPC3 in blood, a sandwich assay was constructed using an antibody recognizing the $\mathrm{N}$-terminus for capture and an antibody recognizing the $\mathrm{C}$-terminus for detection. The determination range of FL-GPC3 by this method was $2-1,500 \mathrm{pg} / \mathrm{ml}$ (Fig. 1B). The coefficient of variation for the three measurements was less than $5 \%$, demonstrating that our method measured FL-GPC3 with a very high precision. In addition, recombinant GPC3 spiked into GPC3 negative specimens of healthy subjects showed a clear spike recovery ratio and dilution linearity, indicating that the method was not affected by the plasma matrix (Fig. 1C).

Preoperative plasma FL-GPC3, AFP, and PIVKA-II levels in $H C C$ patients. Preoperative plasma or serum biomarker levels in HCC patients were measured using fully-automated immunoassay systems. The median levels of AFP, PIVKA-II, and FL-GPC3 were 28.5 (5.7-294.6) ng/ml, 97.0 (26.5-294.6) $\mathrm{mAU} / \mathrm{ml}$, and 21.0 (4.0-5.6) pg/ml, respectively (Table I). The median FL-GPC3 level in the recurrence group was $40.8 \mathrm{pg} / \mathrm{ml}$ (range 8.5-64.7), which was significantly higher than that in the non-recurrence group $(3.3 \mathrm{pg} / \mathrm{ml}$, range 2.9-10.2, P<0.01) (Table II; Fig. 2A). By contrast, there were no significant differences in median AFP or PIVKA-II levels between the two groups (recurrence group vs. non-recurrence group: AFP; 35.7 [range, 10.2-420.5] ng/ml vs. 5.7 [range, 3.6-59.8] ng/ml, P=0.06, PIVKA-II; 208.0 [range, 25.0-822.0] $\mathrm{mAU} / \mathrm{ml}$ vs. 67.0 [range, 30.0-91.0] $\mathrm{mAU} / \mathrm{ml}$, $\mathrm{P}=0.37$ ) (Table II; Fig. 2B and C). Weak correlations between FL-GPC3 and AFP, AFP and PIVKA-II were observed (Fig. 2D-F). No other patient background factors, including tumor size, were significantly associated with FL-GPC3 levels.

FL-GPC3 predicts HCC recurrence within four years of surgery more precisely than the two existing biomarkers. ROC analysis was used to verify whether each biomarker could be used to classify each group. The AUC value of the ROC curve was highest for FL-GPC3, followed by AFP and PIVKA-II 
Table II. Characteristics of patients in the recurrence and non-recurrence groups.

\begin{tabular}{|c|c|c|c|c|}
\hline Variables & Recurrence $(n=28)$ & Non-recurrence $(n=11)$ & $\begin{array}{l}\text { Fisher's exact } \\
\text { test P-values }\end{array}$ & $\begin{array}{l}\text { Mann-Whitney } \\
\text { U test P-values }\end{array}$ \\
\hline Age & & & 0.069 & \\
\hline$\geq 65$ & 8 & 7 & & \\
\hline$<65$ & 20 & 4 & & \\
\hline Sex & & & 0.400 & \\
\hline Male & 21 & 10 & & \\
\hline Female & 7 & 1 & & \\
\hline Liver condition & & & 0.044 & \\
\hline Cirrhosis & 23 & 5 & & \\
\hline Chronic hepatitis or other & 5 & 6 & & \\
\hline $\mathrm{HCV}$ infection & & & 0.471 & \\
\hline Positive & 18 & 5 & & \\
\hline Negative & 10 & 6 & & \\
\hline HBV infection & & & 0.400 & \\
\hline Positive & 7 & 1 & & \\
\hline Negative & 12 & 10 & & \\
\hline Stage & & & 0.446 & \\
\hline I or II & 18 & 9 & & \\
\hline III or IV & 10 & 2 & & \\
\hline Number of tumors & & & 1.000 & \\
\hline Solitary & 22 & 9 & & \\
\hline Multiple & 6 & 2 & & \\
\hline Tumor size (mm) & & & 0.477 & \\
\hline$\geq 5$ & 12 & 3 & & \\
\hline$<50$ & 16 & 8 & & \\
\hline Vascular invasion & & & 0.383 & \\
\hline Present & 9 & 2 & & \\
\hline Absent & 19 & 9 & & \\
\hline Differentiation of tumor & & & 0.259 & \\
\hline Well or moderately & 25 & 11 & & \\
\hline Poorly & 3 & 0 & & \\
\hline AFP (ng/ml), median (range) & $35.7(10.2-420.5)$ & $5.7(3.6-59.8)$ & & 0.057 \\
\hline PIVKA-II (mAU/ml), median (range) & $208.0(25.0-822.0)$ & $67.0(30.0-91.0)$ & & 0.365 \\
\hline FL-GPC3 (pg/ml), median (range) & $40.8(8.5-64.7)$ & $3.3(2.9-10.2)$ & & 0.002 \\
\hline$\geq 14.4$ & 9 & 10 & 0.001 & \\
\hline$<14.4$ & 19 & 1 & & \\
\hline Recurrence within 1 year & & - & - & \\
\hline Yes & 15 & & & \\
\hline No & 13 & & & \\
\hline
\end{tabular}

$\mathrm{HCV}$, hepatitis C virus; HBV, hepatitis B virus; AFP, alpha-fetoprotein; PIVKA-II, protein induced by vitamin K absence or antagonist-II; FL-GPC3, full-length glypican-3.

(0.830, 0.698, and 0.594, respectively; Fig. 3A). When the cutoff value of FL-GPC3 was set to $14.4 \mathrm{pg} / \mathrm{ml}$ based on the Youden index, the positive rate of FL-GPC3 in the recurrence group was 68\% (19/28), which was higher than the 9\% (1/11) in the non-recurrence group (Table II). Next, the disease-free survival (DFS) periods in patients with high $(\geqq 14.4 \mathrm{pg} / \mathrm{ml}$, $\mathrm{n}=20)$ and low $(<14.4 \mathrm{pg} / \mathrm{ml}, \mathrm{n}=19)$ FL-GPC3 levels were analyzed and compared using Kaplan-Meier survival analysis and log rank test, which revealed significant differences in both groups $(60.0 \%$ vs. $15.8 \%$ and $95.0 \%$ vs. $47.4 \%$, at $1-$ and 4-year recurrence rates, respectively; $\mathrm{P}=0.005,0.001$; Fig. 3B). This clearly supports that FL-GPC3 is a predictive marker of HCC recurrence that is equal to or better than AFP and PIVKA-II (Fig. S1A and B). 

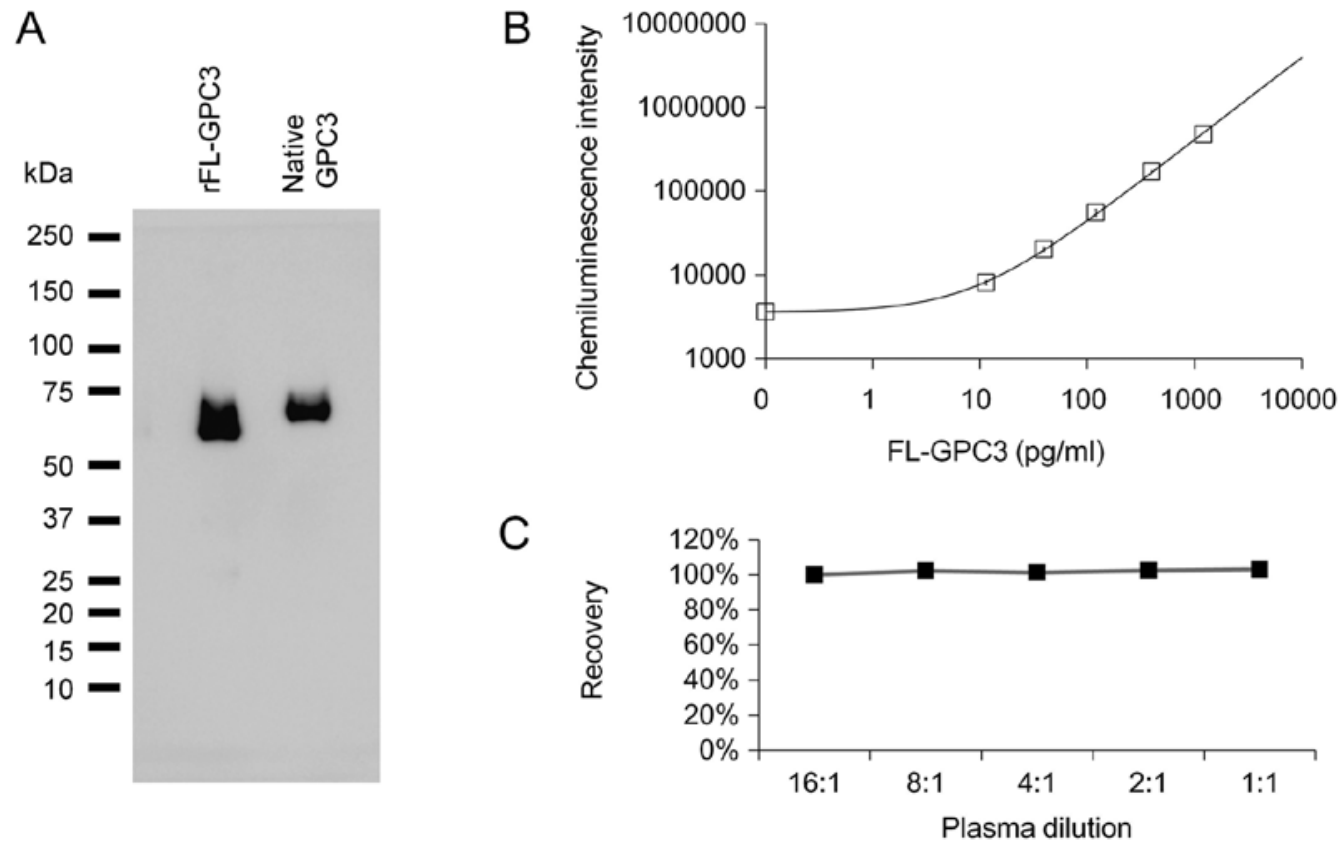

Figure 1. Characterization of native GPC3 and the development of its measurement system. (A) FL-GPC3 expression was confirmed by western blot analysis The left line represents rFL-GPC3 and the right line presents the immunoprecipitation product from HepG2 culture supernatants (presented as native GPC3). (B) The calibration curve for the measurement of FL-GPC3 is presented. rFL-GPC3 was used as the standard (15-1,500 pg/ml). Concentrations of FL-GPC3 were determined by a four parameter logistic model. (C) The assay linearity of dilution was evaluated. GPC3, glypican-3; rFL-GPC3, recombinant full-length glypican-3.
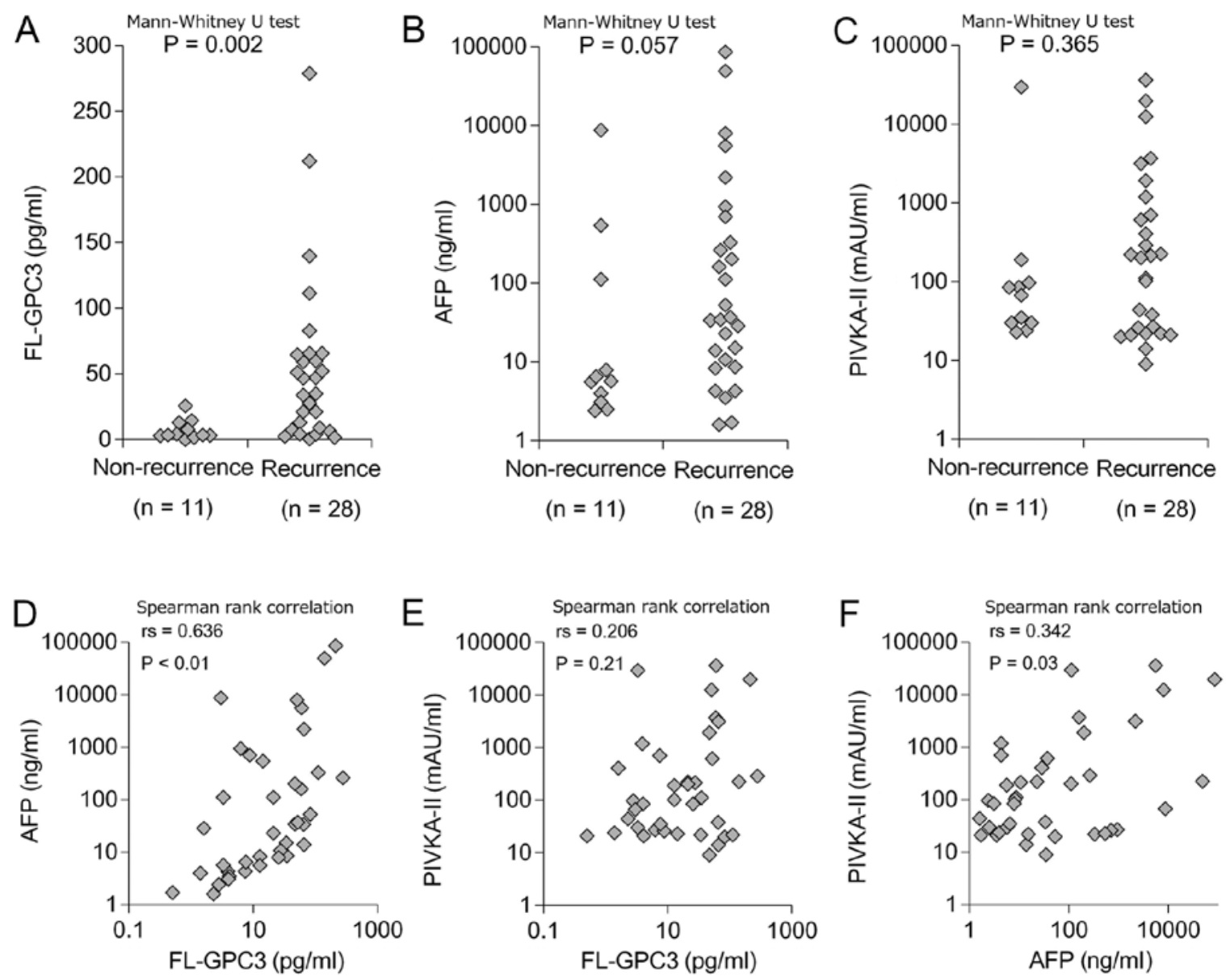

Figure 2. Measurement of plasma FL-GPC3 and other biomarkers in patients with HCC. Levels of (A) FL-GPC3, (B) AFP and (C) PIVKA-II in the recurrence and non-recurrence groups are presented. The P-values of the Mann-Whitney U test are presented in each figure. Correlations between (D) FL-GPC3 and AFP, (E) FL-GPC3 and PIVKA-II, and (F) AFP and PIVKA-II are detailed. The values for $r$ and P (Spearman rank correlation) are included in each figure. HCC, hepatocellular carcinoma; FL-GPC3, full-length glypican-3; AFP, alpha-fetoprotein; PIVKA-II protein induced by vitamin K absence or antagonist-II. 
Table III. Patient characteristics in the two groups, early recurrence or others.

\begin{tabular}{|c|c|c|c|c|}
\hline Variables & $\begin{array}{l}\text { Early } \\
\text { recurrence } n=15\end{array}$ & Other $n=24$ & $\begin{array}{l}\text { Fisher's exact } \\
\text { test P-values }\end{array}$ & $\begin{array}{l}\text { Mann-Whitney } \\
\text { U test P-values }\end{array}$ \\
\hline
\end{tabular}

Age
$\geq 65$
$<65$
Sex
Male
Female
Liver condition
Cirrhosis or chronic hepatitis
Other
HCV infection
Positive
Negative
HBV infection $(+/-)$
Positive
Negative
Stage
I or II
III or IV
Number of tumors
Solitary
Multiple
Tumor size (mm)
$\geq 50$
$<50$

$12 \quad 12$

$3-12$

$4 \quad 4$

1120

$14 \quad 14$

1210

$11-12$

$4 \quad 12$

$3-5$

$12 \quad 19$

$6-6$

9218

325

$12 \quad 19$

$8 \quad 7$

$7-17$

Vascular invasion (+/-)

Present

$\begin{array}{ll}7 & 4\end{array}$

Absent

820

Differentiation of tumor

Well or moderately

Poorly

AFP (ng/ml), median (range)

14

1

2

2

0

0.018

0

2

19

8

19

7

4
20

$\begin{array}{lccc}\text { PIVKA-II (mAU/ml), median (range) } & 226.0(156.0-2532.0) & 36.5(22.8-120.3) & 0.008 \\ \text { FL-GPC3 }(\mathrm{pg} / \mathrm{ml}), \text { median (range) } & 46.7(21-62.4) & 6.9(3.2-37.2) & 0.014\end{array}$

HCV, hepatitis C virus; HBV, hepatitis B virus; AFP, alpha-fetoprotein; PIVKA-II, protein induced by vitamin K absence or antagonist-II; FL-GPC3, full-length glypican-3.

Combining three biomarkers enabled better prediction of HCC recurrence within one year of surgery. Having demonstrated that FL-GPC3 is a predictive marker of $\mathrm{HCC}$ recurrence within four years, we evaluated whether earlier recurrence (i.e., within one year) could be predicted. Patients with recurrence were divided into an early recurrence group $(n=15)$, which showed recurrence within one year, and a second group with later recurrence or no recurrence $(n=24)$. Biomarker levels were then compared between groups (Table III). Significant differences were observed for FL-GPC3 (46.2 pg/ml vs. $6.9 \mathrm{pg} / \mathrm{ml}$, $\mathrm{P}=0.014)$, AFP (160.2 ng/ml vs. $10.9 \mathrm{ng} / \mathrm{ml}, \mathrm{P}=0.026)$, and PIVKA-II (226.0 $\mathrm{mAU} / \mathrm{ml}$ vs. $36.5 \mathrm{mAU} / \mathrm{ml}, \mathrm{P}=0.008)$.
However, the AUC value of the ROC curve obtained for each biomarker was not high enough to be practical. The sensitivity of each marker for predicting early recurrence was high (FL-GPC3 93.3\%, AFP 93.3\%, PIVKA-II 86.7\%), but the specificity was insufficient (FL-GPC3 45.8\%, AFP 58.3\%, PIVKA-II $47.8 \%$ ) when the cutoff values of each marker was set based on the Youden index (FL-GPC3 $>8.0 \mathrm{pg} / \mathrm{ml}$, AFP $>7.9 \mathrm{ng} / \mathrm{ml}$, PIVKA-II $>102.0 \mathrm{mAU} / \mathrm{ml}$ ) (Fig. 4A). Thus, we examined whether combining the three values was effective for predicting recurrence. Of the total patients, 14/39 (36\%) were positive for all three markers, and these patients tended to face recurrence at an earlier stage than other patients (rates of recurrence within 

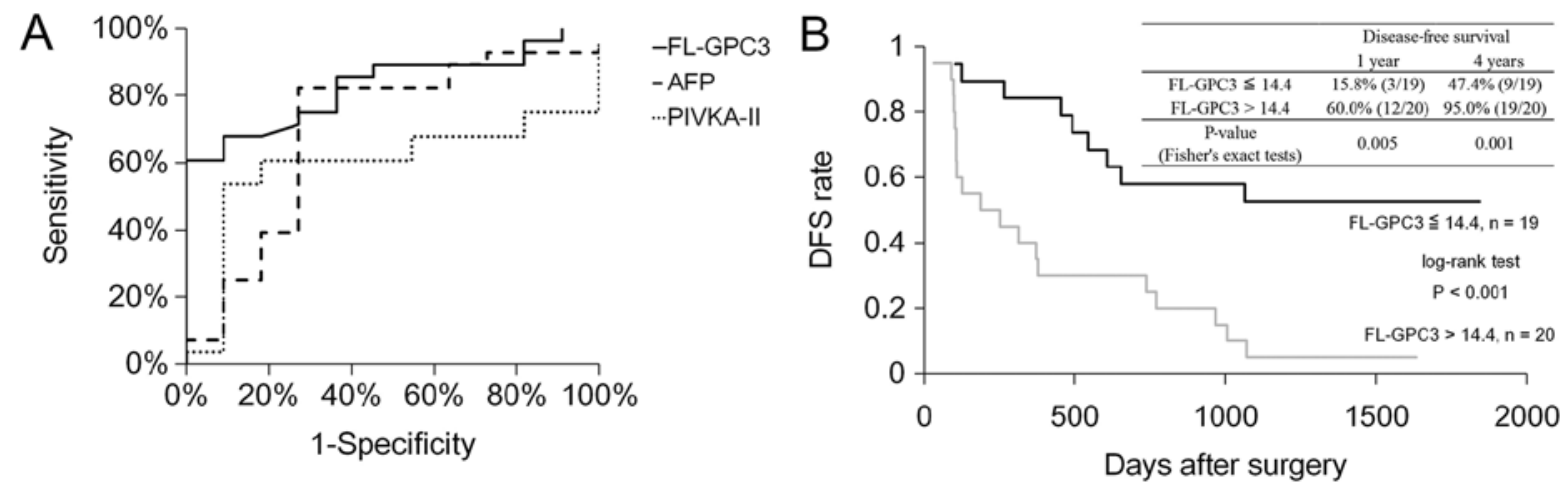

Figure 3. ROC and Kaplan-Meier survival curves for DFS after surgery. (A) ROC curves of FL-GPC3, AFP and PIVKA-II are presented. The area under the ROC curve value for AFP, PIVKA-II and FL-GPC3 was 0.830 (95\% confidence interval, 0.957-0.702), 0.698 (0.893-0.503) and 0.594 (0.782-0.406), respectively. (B) Kaplan-Meier curves of DFS in patients with low $(\leq 14.4 \mathrm{pg} / \mathrm{ml}, \mathrm{n}=19)$ and high $(>14.4 \mathrm{pg} / \mathrm{ml}, \mathrm{n}=20)$ FL-GPC 3 are presented. The P-value of the log rank test was 0.0004. ROC, receiver operating characteristic; DFS, disease-free survival; FL-GPC3, full-length glypican-3; AFP, alpha-fetoprotein; PIVKA-II protein induced by vitamin $\mathrm{K}$ absence or antagonist-II.
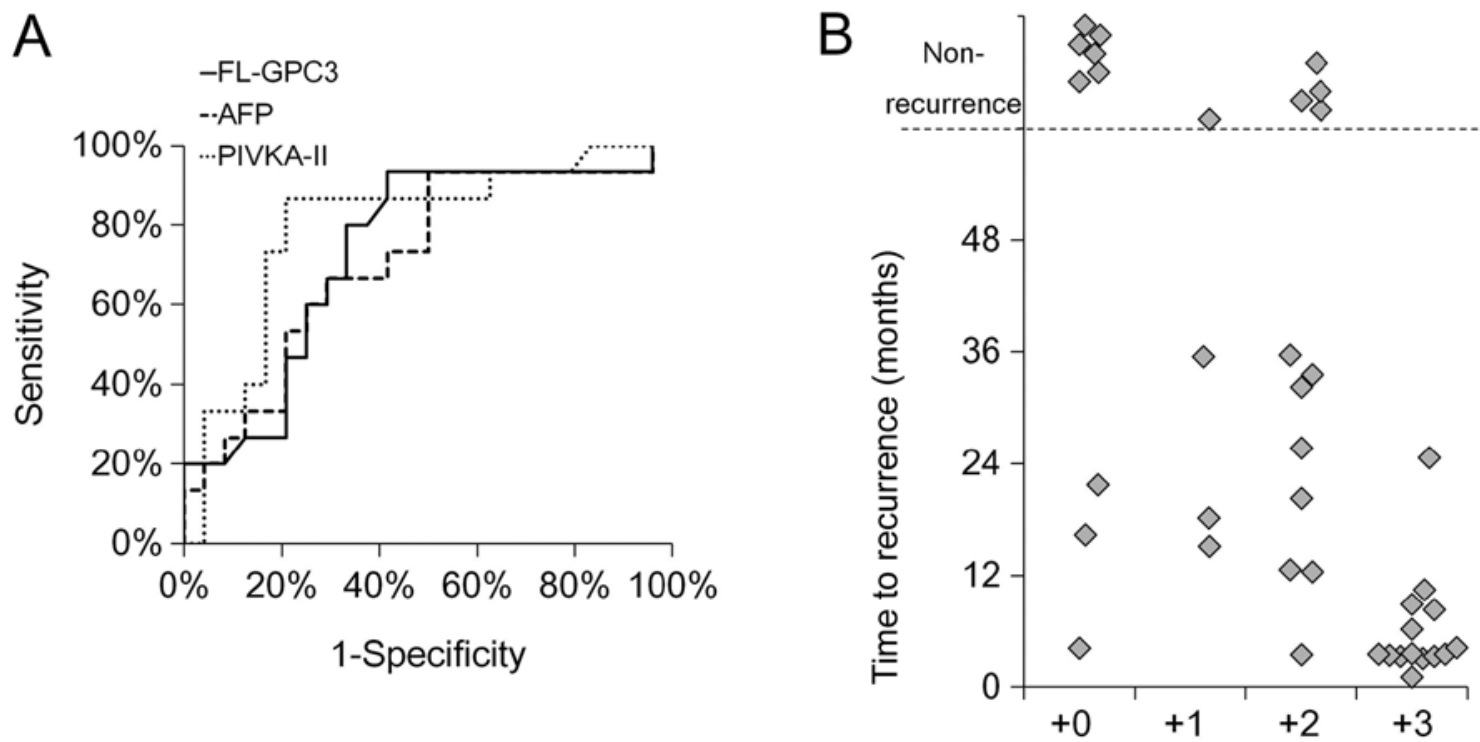

Figure 4. Early recurrence prediction by FL-GPC3, AFP, PIVKA-II and their combinations. (A) ROC curves of FL-GPC3, AFP and PIVKA-II for the diagnosis of HCC recurrence within one year of surgery are presented. The area under the ROC curve values for each marker was 0.736 ( $95 \%$ confidence interval, $0.820-0.652), 0.714$ (0.809-0.619) and 0.757 (0.837-0.677), respectively. The cutoff values for each marker were set based on the Youden index (FL-GPC3 $>8.0 \mathrm{pg} / \mathrm{ml}$, AFP $>7.9 \mathrm{ng} / \mathrm{ml}$ and PIVKA-II $>102.0 \mathrm{mAU} / \mathrm{ml}$ ). (B) The associations between time to recurrence and positive numbers of FL-GPC3, AFP and PIVKA-II are presented. Plus three, two and one indicates the patients that were positive for all three, two or one marker respectively. Plus zero indicates the patients that were positive for no markers. The cutoff value of each marker was FL-GPC3 $>8.0 \mathrm{pg} / \mathrm{ml}$, AFP $>7.9 \mathrm{ng} / \mathrm{ml}$ and PIVKA-II $>102.0 \mathrm{mAU} / \mathrm{ml}$. Each patient is indicated by a dot. FL-GPC3, full-length glypican-3; AFP, alpha-fetoprotein; PIVKA-II protein induced by vitamin K absence or antagonist-II; HCC, hepatocellular carcinoma; ROC, receiver operating characteristic.

1 year, 93\% (13/14) vs. 8\% (2/25), $\mathrm{P}<0.001)$ (Table IV). The sensitivity and specificity to predict recurrence within 1 year were 86.6 and $95.8 \%$, respectively (Fig. 4B). Therefore, by using three biomarkers in combination, patients likely to face recurrence within one year of surgery could be predicted with a very high sensitivity and specificity.

\section{Discussion}

To formulate effective treatment policies, it is crucial to know the risk of recurrence of HCC before treatment. Our study has shown that HCC patients with high FL-GPC3 levels have a higher risk of recurrence within four years, and that there is no significant correlation between FL-GPC3 level and tumor diameter. This finding is consistent with previous reports $(26,27)$. It has been reported that GPC3 is expressed in cancerous cells as well as non-cancerous surrounding cells, and that the prognosis of GPC3-positive HCC patients is poor $(12,14,28,29)$. This may indicate that FL-GPC3 is produced by the tumor itself but as well as by precancerous lesions located in the surrounding liver tissue. Thus, it is possible that FL-GPC3 could be used as a biomarker to qualitatively evaluate the malignancy of a tumor and its surrounding environment.

In the present study, we revealed that patients positive for all three markers (FL-GPC3, AFP and PIVKA-II) were likely to face $\mathrm{HCC}$ recurrence within one year. In addition, a weak correlation was found between FL-GPC3 and AFP 
Table IV. Patient characteristics in two groups classified according to the marker positive number.

\begin{tabular}{|c|c|c|c|c|}
\hline Variables & $\begin{array}{l}\text { Three positive } \\
\text { groups } n=14\end{array}$ & Other $n=25$ & $\begin{array}{c}\text { Fisher's exact } \\
\text { test P-values }\end{array}$ & $\begin{array}{l}\text { Mann-Whitney } \\
\text { U test P-values }\end{array}$ \\
\hline Age & & & 0.342 & \\
\hline$\geq 65$ & 10 & 14 & & \\
\hline$<65$ & 4 & 11 & & \\
\hline Sex (male/female) & & & 0.916 & \\
\hline Male & 3 & 5 & & \\
\hline Female & 11 & 20 & & \\
\hline Liver condition & & & 0.029 & \\
\hline Cirrhosis or chronic hepatitis & 13 & 15 & & \\
\hline Other & 1 & 10 & & \\
\hline HCV infection & & & 0.237 & \\
\hline Positive & 10 & 13 & & \\
\hline Negative & 4 & 12 & & \\
\hline HBV infection & & & 0.471 & \\
\hline Positive & 2 & 6 & & \\
\hline Negative & 12 & 19 & & \\
\hline Stage & & & 0.221 & \\
\hline I or II & 6 & 6 & & \\
\hline III or IV & 8 & 19 & & \\
\hline Number of tumors & & & 0.916 & \\
\hline Solitary & 3 & 5 & & \\
\hline Multiple & 11 & 20 & & \\
\hline Tumor size (mm) & & & 0.073 & \\
\hline$\geq 50$ & 8 & 7 & & \\
\hline$<50$ & 6 & 18 & & \\
\hline Vascular invasion & & & 0.024 & \\
\hline Present & 7 & 4 & & \\
\hline Absent & 7 & 21 & & \\
\hline Differentiation of tumor & & & 0.923 & \\
\hline Well or moderately & 13 & 23 & & \\
\hline Poorly & 1 & 2 & & \\
\hline AFP (ng/ml), median (range) & $180.9(26.4-4701.8)$ & $7.9(4.0-52.6)$ & & 0.004 \\
\hline PIVKA-II (mAU/ml), median (range) & $450.5(216.5-3555.5)$ & $30.0(22.0-85.0)$ & & 0.000 \\
\hline FL-GPC3 (pg/ml), median (range) & $51.5(29.5-64)$ & $6.3(3.0-25.6)$ & & 0.001 \\
\hline Recurrence within 1 year $(+/-)$ & & & $<0.001$ & \\
\hline Yes & 13 & 2 & & \\
\hline No & 1 & 23 & & \\
\hline
\end{tabular}

Three positive groups (AFP+, PIVKA-II+, FL-GPC3+) were compared with two positive, one positive and all negative groups. HCV, hepatitis C virus; HBV, hepatitis B virus; AFP, alpha-fetoprotein; PIVKA-II, protein induced by vitamin K absence or antagonist-II; FL-GPC3, full-length glypican-3.

and between AFP and PIVKA-II. It is known that a high value of AFP or PIVKA-II is a poor prognosis marker of HCC $(30,31)$. Our study showed that high levels of FL-GPC3 were strongly related to $\mathrm{HCC}$ recurrence, and this might also reflect poor prognosis. Both AFP and GPC3 are known as fetal cancer antigens. Our study shows a correlation between the two, but FL-GPC3 did not correlate with tumor size, whereas AFP is known to correlate well with tumor size (32). Therefore, even if AFP and FL-GPC3 are the same fetal cancer antigen, they may reflect some different factors that contribute to cancer recurrence. In addition, since there is no correlation between FL-GPC3 and PIVKA-II, it can be said that it also reflects different risk factors for recurrence. Our study shows a correlation between AFP and PIVKA-II, 
both of which are known to correlate with tumor size $(32,33)$. However, AFP is elevated in poorly differentiated hepatocytes, and high levels of PIVKA-II are said to suggest the presence of vascular invasion (34). This suggests that AFP and PIVKA-II also reflect different recurrence risk factors. Based on these facts, FL-GPC3, AFP, and PIVKA-II are all considered to be markers that reflect different cancer states and risk of recurrence. While expression of any of these three markers could indicate poor prognosis, patients with high levels of all three markers are thought to be at very high risk of early recurrence due to predisposition to cancer development, even though there is a weak correlation among these markers. Our results show that patients with early recurrence have a high prevalence of background liver disease and a high incidence of vascular invasion, which is consistent with previous reports (35). Patients with these backgrounds still need careful follow-up as patients with high recurrence risk. On the other hand, there was one early recurrence in a patient who had neither vascular invasion nor background liver disease, and this case showed high values for FL-GPC3, AFP, and PIVKA-II. As the sample set used in this study is relatively small, further case studies will need to be added. However, the measurement of the three markers may be useful in screening for patients with high-early recurrence risk that may be overlooked by background liver disease or vascular invasion alone. In addition, the presence or absence of mild vascular invasion cannot be known until a histopathological examination after surgery. Our finding that patients who are positive for all three markers are more likely to have early recurrence, so that they know the patient's risk of early recurrence before treatment. Better knowledge of the risk of recurrence will allow a more optimal treatment method to be selected for each patient, promoting the development of personalized medicine. Future efforts to develop new therapies combating $\mathrm{HCC}$ recurrence would benefit from the selection of patients with high recurrence risk as well as the possibility of reducing side effect risk. Diagnosis of HCC recurrence risk by FL-GPC3 measurement may become a crucial diagnostic technique in the future.

In the present study, the median concentration of FL-GPC3 in the blood of HCC patients was $21.0 \mathrm{pg} / \mathrm{ml}$, which is lower than previously reported levels $(400-99,940 \mathrm{pg} / \mathrm{ml})(15,19,20)$. This difference could be because the previously reported assays were for N-terminal GPC3, which measures both N-terminal and the full-length protein, whereas our assay measured only the latter. As our assay requires the formation of a sandwich by antibodies simultaneously recognizing the $\mathrm{N}$ - and C-terminal sides, it enables measurement of only FL-GPC3. By contrast, both the $\mathrm{N}$-terminal domain and full-length protein were measured in a previous study using a pair of antibodies specific to the N-terminal domain. The correlation between GPC3 and other markers remains controversial $(15,26,28)$ but may be explained by the target form of GPC3 in each report. It is not clear what form of GPC3-whether the N-terminal domain, the full-length protein, or the combination of the two-more closely reflects the prognosis of HCC. A comparative study between N-terminal GPC3 and our assay in the same group of patients would be required to confirm this. Verification studies performed for all GPC3 forms in the same patient group could address this problem.
Further, while the present study focused on predicting the risk of post-operative HCC recurrence, FL-GPC3 measurement could be expanded to predict HCC occurrence in patients with chronic hepatitis $(\mathrm{CH})$ or LC. Past studies have shown that the N-terminal form of GPC3 does not increase in these patients $(19,21)$, but FL-GPC3 has not yet been investigated. Comparing the levels of FL-GPC3 in patients with $\mathrm{HCC}, \mathrm{CH}$, or LC and healthy volunteers could give a clear idea of the normal level of this protein and help identify the point at which FL-GPC3 levels increase in blood. We hope that the utility of FL-GPC3 as a biomarker will be further investigated in larger scale, multi-center cohort studies.

\section{Acknowledgements}

A patent application has been filed relating to this work. Inventors: Tetsuya Nakatsura, Keigo Saito, Masahiro Miura, Kozo Suto and Takuya Iino. Title, method for assisting prediction of recurrence risk in HCC patient, device, computer program product, and kit. Patent code: JP Patent 6292564. Date filed, March 6, 2017. Date issued, February 23, 2018.

\section{Funding}

The present study was supported by the National Cancer Center Research and Development Fund (grant nos. 25-A-7 and 28-A-8), as well as joint research funding from Sysmex Co., Ltd.

\section{Availability of data and materials}

The datasets used and/or analyzed during the present study are available from the corresponding author on reasonable request.

\section{Authors' contributions}

$\mathrm{MM}, \mathrm{NF}$, and $\mathrm{KSa}$ and $\mathrm{KSu}$ constructed the measurement system of FL-GPC3 and analyzed the patient data. YS, SM, and TS analyzed and interpreted the patient data. MK, ST and NG collected samples and suggested the clinical utility of FL-GPC3. TY and TN were major contributors in the conception and designing of the current study. All authors read and approved the final manuscript.

\section{Ethics approval and consent to participate}

The present study was approved by the Research Ethics Committee of the National Cancer Center of Japan and Sysmex Corporation. Informed consent was obtained from all patients.

\section{Patient consent for publication}

Written consent for publication was obtained from all patients.

\section{Competing interests}

TN was supported by fundamental research funding obtained from Sysmex Co., Ltd. The remaining authors declare that they have no competing interests. 


\section{References}

1. Jemal A, Bray F, Center MM, Ferlay J, Ward E and Forman D: Global cancer statistics. CA Cancer J Clin 61: 69-90, 2011.

2. Sawada Y, Yoshikawa T, Ofuji K, Yoshihura M, Tsuchiya N, Takahashi M, Nobuoka D, Gotohda N, Takahashi S, Kato Y, et al: Phase II study of the GPC3-derived peptide vaccine as an adjuvant therapy for hepatocellular carcinoma patients. Oncoimmunology 5: e1129483, 2016.

3. Toyoda H, Kumada T, Osaki Y, Oka H, Urano F, Kudo M and Matsunaga T: Staging hepatocellular carcinoma by a novel scoring system (BALAD score) based on serum markers. Clin Gastroenterol Hepatol 4: 1528-1536, 2006.

4. Carr BI, Kanke F, Wise M and Satomura S: Clinical evaluation of lens culinaris agglutinin-reactive alpha-fetoprotein and des-gamma-carboxy prothrombin in histologically proven hepatocellular carcinoma in the United States. Dig Dis Sci 52: 776-782, 2007

5. Bayati N, Silverman AL and Gordon SC: Serum alpha-fetoprotein levels and liver histology in patients with chronic hepatitis C. Am J Gastroenterol 93: 2452-2456, 1998.

6. Shirakawa H, Kuronuma T, Nishimura Y, Hasebe T, Nakano M, Gotohda N, Takahashi S, Nakagohri T, Konishi M, Kobayashi N, et al: Glypican-3 is a useful diagnostic marker for a component of hepatocellular carcinoma in human liver cancer. Int J Oncol 34: 649-656, 2009.

7. Shirakawa H, Suzuki H, Shimomura M, Kojima M, Gotohda N Takahashi S, Nakagohri T, Konishi M, Kobayashi N, Kinoshita T and Nakatsura T: Glypican-3 expression is correlated with poor prognosis in hepatocellular carcinoma. Cancer Sci 100: 1403-1407, 2009.

8. Wang HL, Anatelli F, Zhai QJ, Adley B, Chuang ST and Yang XJ: Glypican-3 as a useful diagnostic marker that distinguishes hepatocellular carcinoma from benign hepatocellular mass lesions. Arch Pathol Lab Med 132: 1723-1728, 2008.

9. Nakatsura T, Kageshita T, Ito S, Wakamatsu K, Monji M, Ikuta Y, Senju S, Ono T and Nishimura Y: Identification of glypican-3 as a novel tumor marker for melanoma. Clin Cancer Res 10: 6612-6621, 2004.

10. Toretsky JA, Zitomersky NL, Eskenazi AE, Voigt RW, Strauch ED, Sun CC, Huber R, Meltzer SJ and Schlessinger D: Glypican-3 expression in Wilms tumor and hepatoblastoma. J Pediatr Hematol Oncol 23: 496-499, 2001.

11. Saikali Z and Sinnett D: Expression of glypican 3 (GPC3) in embryonal tumors. Int J Cancer 89: 418-422, 2000.

12. Capurro M, Wanless IR, Sherman M, Deboer G, Shi W, Miyoshi E and Filmus J: Glypican-3: A novel serum and histochemical marker for hepatocellular carcinoma. Gastroenterology 125 89-97, 2003.

13. De Cat B, Muyldermans SY, Coomans C, Degeest G, Vanderschueren B, Creemers J, Biemar F, Peers B and David G: Processing by proprotein convertases is required for glypican-3 modulation of cell survival, Wnt signaling, and gastrulation movements. J Cell Biol 163: 625-635, 2003.

14. Ho M and Kim H: Glypican-3: A new target for cancer immunotherapy. Eur J Cancer 47: 333-338, 2011

15. Haruyama Y, Yorita K, Yamaguchi T, Kitajima S, Amano J, Ohtomo T, Ohno A, Kondo K and Kataoka H: High preoperative levels of serum glypican-3 containing $\mathrm{N}$-terminal subunit are associated with poor prognosis in patients with hepatocellular carcinoma after partial hepatectomy. Int J Cancer 137: 1643-1651, 2015.

16. Nakatsura T, Yoshitake Y, Senju S, Monji M, Komori H, Motomura Y, Osaka S, Beppu T, Ishiko T, Kamohara H, et al: Glypican-3, overexpressed specifically in human hepatocellular carcinoma, is a novel tumor marker. Biochem Biophys Res Commun 306: 16-25, 2003.

17. Filmus J, Capurro M and Rast J: Glypicans. Genome Biol 9: 224, 2008

18. Capurro M and Filmus J: Glypican-3 as a serum marker for hepatocellular carcinoma. Cancer Res 65: 372-373, 2005.

19. Hippo Y, Watanabe K, Watanabe A, Midorikawa Y, Yamamoto S, Ihara S, Tokita S, Iwanari H, Ito Y, Nakano K, et al: Identification of soluble NH2-terminal fragment of glypican-3 as a serological marker for early-stage hepatocellular carcinoma. Cancer Res 64: $418-423,2004$
20. Chen M, Li G, Yan J, Lu X, Cui J, Ni Z, Cheng W, Qian G, Zhang J and Tu H: Reevaluation of glypican-3 as a serological marker for hepatocellular carcinoma. Clin Chim Acta 423: 105-111, 2013.

21. Beale G, Chattopadhyay D, Gray J, Stewart S, Hudson M, Day C, Trerotoli P, Giannelli G, Manas D and Reeves H: AFP, PIVKAII, GP3, SCCA-1 and follisatin as surveillance biomarkers for hepatocellular cancer in non-alcoholic and alcoholic fatty liver disease. BMC Cancer 8: 200, 2008.

22. Ozkan H, Erdal H, Kocak E, Tutkak H, Karaeren Z, Yakut M and Koklu S: Diagnostic and prognostic role of serum glypican 3 in patients with hepatocellular carcinoma. J Clin Lab Anal 25: 350-353, 2011.

23. Capurro M, Shi W, Izumikawa T, Kitagawa $\mathrm{H}$ and Filmus J: Processing by convertases is required for glypican-3-induced inhibition of Hedgehog signaling. J Biol Chem 290: 7576-7585, 2015.

24. Poon RT, Ng IO, Fan ST, Lai EC, Lo CM, Liu CL and Wong J: Clinicopathologic features of long-term survivors and disease-free survivors after resection of hepatocellular carcinoma: A study of a prospective cohort. J Clin Oncol 19: 3037-3044, 2001.

25. Gao W, Tang Z, Zhang YF, Feng M, Qian M, Dimitrov DS and Ho M: Immunotoxin targeting glypican-3 regresses liver cancer via dual inhibition of Wnt signalling and protein synthesis. Nat Commun 6: 6536, 2015.

26. El-Saadany S, El-Demerdash T, Helmy A, Mayah WW, Hussein BE, Hassanien M, Elmashad N, Fouad MA and Basha EA: Diagnostic value of Glypican-3 for hepatocellular carcinomas. Asian Pac J Cancer Prev 19: 811-817, 2018.

27. Chen IP, Ariizumi S, Nakano M and Yamomoto M: Positive glypican-3 expression in early hepatocellular carcinoma predicts recurrence after hepatectomy. J Gastroenterol 49: 117-125, 2014.

28. Ofuji K, Saito K, Suzuki S, Shimomura M, Shirakawa H, Nobuoka D, Sawada Y, Yoshimura M, Tshuchiya N, Takahashi M, et al: Perioperative plasma glypican-3 level may enable prediction of the risk of recurrence after surgery in patients with stage I hepatocellular carcinoma. Oncotarget 8: 37835-37844, 2017.

29. Kaseb AO, Hassan M, Lacin S, Abdel-Wahab R, Amin HM, Shalaby A, Wolff RA, Yao J, Rashid A, Vennapusa B, et al: Evaluating clinical and prognostic implications of Glypican-3 in hepatocellular carcinoma. Oncotarget 7: 69916-69926, 2016.

30. Imamura H, Matsuyama Y, Tanaka E, Ohkubo T, Hasegawa K, Miyagawa S, Sugawara Y, Minagawa M, Takayama T, Kawasaki S and Makuuchi M: Risk factors contributing to early and late phase intrahepatic recurrence of hepatocellular carcinoma after hepatectomy. J Hepatol 38: 200-207, 2003.

31. Zhang D, Liu Z, Yin X, Qi X, Lu B, Liu Y and Hou J: Prognostic value of PIVKA-II in hepatocellular carcinoma patients receiving curative ablation: A systematic review and meta-analysis. Int J Biol Markers 33: 266-274, 2018.

32. Abbasi A, Bhutto AR, Butt N and Munir SM: Corelation of serum alpha fetoprotein and tumor size in hepatocellular carcinoma. J Pak Med Assoc 62: 33-36, 2012.

33. Poté N, Cauchy F, Albuquerque M, Voitot H, Belghiti J, Castera L, Puy H, Bedossa P and Paradis V: Performance of PIVKA-II for early hepatocellular carcinoma diagnosis and prediction of microvascular invasion. J Hepatol 62: 848-854, 2015.

34. Imamura H, Matsuyama Y, Miyagawa Y, Ishida K, Shimada R, Miyagawa S, Makuuchi $M$ and Kawasaki S: Prognostic significance of anatomical resection and des-gamma-carboxy prothrombin in patients with hepatocellular carcinoma. Br J Surg 86: 1032-1038, 1999.

35. Yamanaka N, Okamoto E, Toyosaka A, Mitunobu M, Fujihara S, Kato T, Fujimoto J, Oriyama T, Furukawa K and Kawamura E: Prognostic factors after hepatectomy for hepatocellular carcinomas. A univariate and multivariate analysis. Cancer 65: 1104-1110, 1990

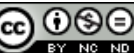

This work is licensed under a Creative Commons Attribution-NonCommercial-NoDerivatives 4.0 International (CC BY-NC-ND 4.0) License. 